\title{
Stereotactic radiofrequency thermocoagulation for giant hypothalamic hamartoma
}

\author{
Hiroshi Shirozu, MD, PhD, ${ }^{1,2}$ Hiroshi Masuda, MD,,2 Yosuke Ito, MD, ${ }^{1,2}$ Masaki Sonoda, MD, ${ }^{1,2}$ and \\ Shigeki Kameyama, MD, PhD ${ }^{1,2}$
}

\begin{abstract}
1Department of Functional Neurosurgery and ${ }^{2}$ Hypothalamic Hamartoma Center, Nishi-Niigata Chuo National Hospital, Niigata, Japan
\end{abstract}

\begin{abstract}
OBJECTIVE The authors undertook this study to validate the feasibility and safety of stereotactic radiofrequency thermocoagulation (SRT) for the surgical treatment of giant hypothalamic hamartoma $(\mathrm{HH})$.

METHODS Of the 109 patients who underwent SRT for hypothalamic hamartoma $(\mathrm{HH})$ at the authors' institution between 1997 and 2013, 16 patients (9 female, 7 male) had giant HHs (maximum diameter $\geq 30 \mathrm{~mm}$ ). The clinical records of these 16 patients were retrospectively reviewed.

RESULTS The patients' age at first SRT ranged from 1 to 22 years (median 5 years). The maximum diameter of their $\mathrm{HHs}$ was $30-80 \mathrm{~mm}$ (mean $38.5 \mathrm{~mm}$ ). Eleven HHs had bilateral attachments to the hypothalamus. All patients had gelastic seizures (GS), and 12 had types of seizures other than GS. Some of these patients also had mental retardation $(n=10,62.5 \%)$, behavioral disorders $(n=8,50.0 \%)$, and precocious puberty $(n=11,68.8 \%)$. A total of 22 SRT procedures were performed; 5 patients underwent repeat SRT procedures. There was no mortality or permanent morbidity. After 17 of the 22 procedures, the patients experienced transient complications, including high fever $(n=7)$, hyperphagia $(n=3)$, hyponatremia $(n=6)$, disturbance of consciousness $(n=1)$, cyst enlargement $(n=1)$, and epidural hematoma ( $n$ =1). Thirteen patients (81.3\%) achieved freedom from GS after the final SRT procedure during a follow-up period ranging from 6 to 60 months (mean 23 months). Twelve patients had non-gelastic seizures in addition to GS, and 7 (58.3\%) of these 12 patients experienced freedom from their non-gelastic seizures.
\end{abstract}

CONCLUSIONS SRT provided minimal invasiveness and excellent seizure outcomes even in patients with giant $\mathrm{HHs}$. Repeat SRT is safe for residual GS. SRT is a feasible single surgical strategy for HH regardless of the tumor's size or shape.

http://thejns.org/doi/abs/10.3171/2015.6.JNS15200

KEY WORDS gelastic seizure; giant hypothalamic hamartoma; stereotactic radiofrequency thermocoagulation; surgical treatment; stereotactic radiosurgery

$\mathrm{H}$ ypothalamic hamartoma $(\mathrm{HH})$ is an intrinsic epileptogenic lesion causing gelastic seizures (GS). HHs also provoke not only other types of seizures but also behavioral and cognitive problems. Because these seizures are medically intractable, surgical treatment is undertaken with the intention of cure. However, with the surgical approach, it is difficult to achieve sufficient treatment of deep-seated HHs surrounded by critical structures. Many reports on surgical treatment have mentioned the high rate of complications.

We have reported the high efficacy and minimal invasiveness of stereotactic radiofrequency thermocoagulation (SRT) in early series. ${ }^{12,15,19,20}$ Although the average size of
HHs is reported to be around 14 to $19 \mathrm{~mm}, 3,11,29$ there are rare cases of giant HHs with a maximum diameter greater than $30 \mathrm{~mm}$. There are several case reports of surgically treated giant $\mathrm{HHs}, 8,13,23,25,27,32,33$ because their sizes and complex shapes can present a challenge to surgery. We have dealt with many giant HHs and have performed SRT for such patients with the same strategy as for HHs of the usual size. We have come to believe that SRT is applicable for any size or shape of $\mathrm{HH}$ because it is a stereotactically secured procedure with minimal invasiveness.

In the present study, the clinical data of our giant $\mathrm{HH}$ cases were retrospectively reviewed to validate the efficacy and safety of SRT.

ABBREVIATIONS AED = antiepileptic drug; EEG = electroencephalography; GKS = Gamma Knife surgery; GS = gelastic seizures; HH = hypothalamic hamartoma; SRT = stereotactic radiofrequency thermocoagulation.

SUBMITTED February 1, 2015. ACCEPTED June 17, 2015.

INCLUDE WHEN CITING Published online January 1, 2016; DOI: 10.3171/2015.6.JNS15200. 


\section{Methods}

\section{Patient Profiles}

Of 109 consecutive patients with $\mathrm{HHs}$ who underwent SRT at Nishi-Niigata Chuo National Hospital between 1997 and 2013, 16 patients (9 female, 7 male) had giant HHs (maximum diameter $\geq 30 \mathrm{~mm}$ ). The clinical records of these 16 cases were analyzed in this study. Preoperative evaluation included clinical history, seizure semiology, neurological examination, neuropsychological tests, endocrinological examination, electroencephalography (EEG), video-EEG, CT, MRI, and interictal and ictal single-photon emission computed tomography (SPECT) with 99mTc-ethylcysteinate dimer.

\section{MRI and Ictal SPECT}

For SRT, lesions were classified on the bases of coronal MR images into intrahypothalamic type, mixed hypothalamic type, and parahypothalamic type according to Kameyama's classification. ${ }^{19}$ The attachment to the hypothalamus was also categorized as unilateral or bilateral attachment based on the continuity with the hypothalamus. Ictal SPECT was analyzed using subtraction ictal SPECT coregistered to MRI (SISCOM). Details of MRI and SISCOM have been described elsewhere. ${ }^{18}$

\section{Surgical Strategy}

The basic SRT procedure has been described previously. ${ }^{19}$ The most important point of the SRT strategy is to achieve sufficient coagulation of the interface of the hamartoma with the hypothalamus. The trajectory of the coagulation probe is set to pass through the interface using 3D image planning software (Leksell SurgiPlan, Elekta). The location of the probe is confirmed by intraoperative fluoroscopy in each trajectory. Deviation within $1 \mathrm{~mm}$ is considered acceptable. If the probe deviates by more than $1 \mathrm{~mm}$, it is reinserted with some adjustment. Then, a coagulation lesion with a 5-mm diameter is created along a trajectory to disconnect the attachment of the hamartoma. For all giant hamartomas, multiple lesions were configured through multiple unilateral trajectories (Fig. 1). Because giant hamartomas have not only a large and complex interface, but also bilateral attachments, the trajectory must be carefully planned. For HHs with bilateral attachments, the approach side is determined by the major attachment to the hypothalamus, the results of SISCOM, and seizure semiology. Some giant $\mathrm{HH}$ cases show an area of increased blood flow on SISCOM at the dominant attachment. This finding is considered to indicate the site of ictogenesis.

Although multi-staged SRT procedures were intention-
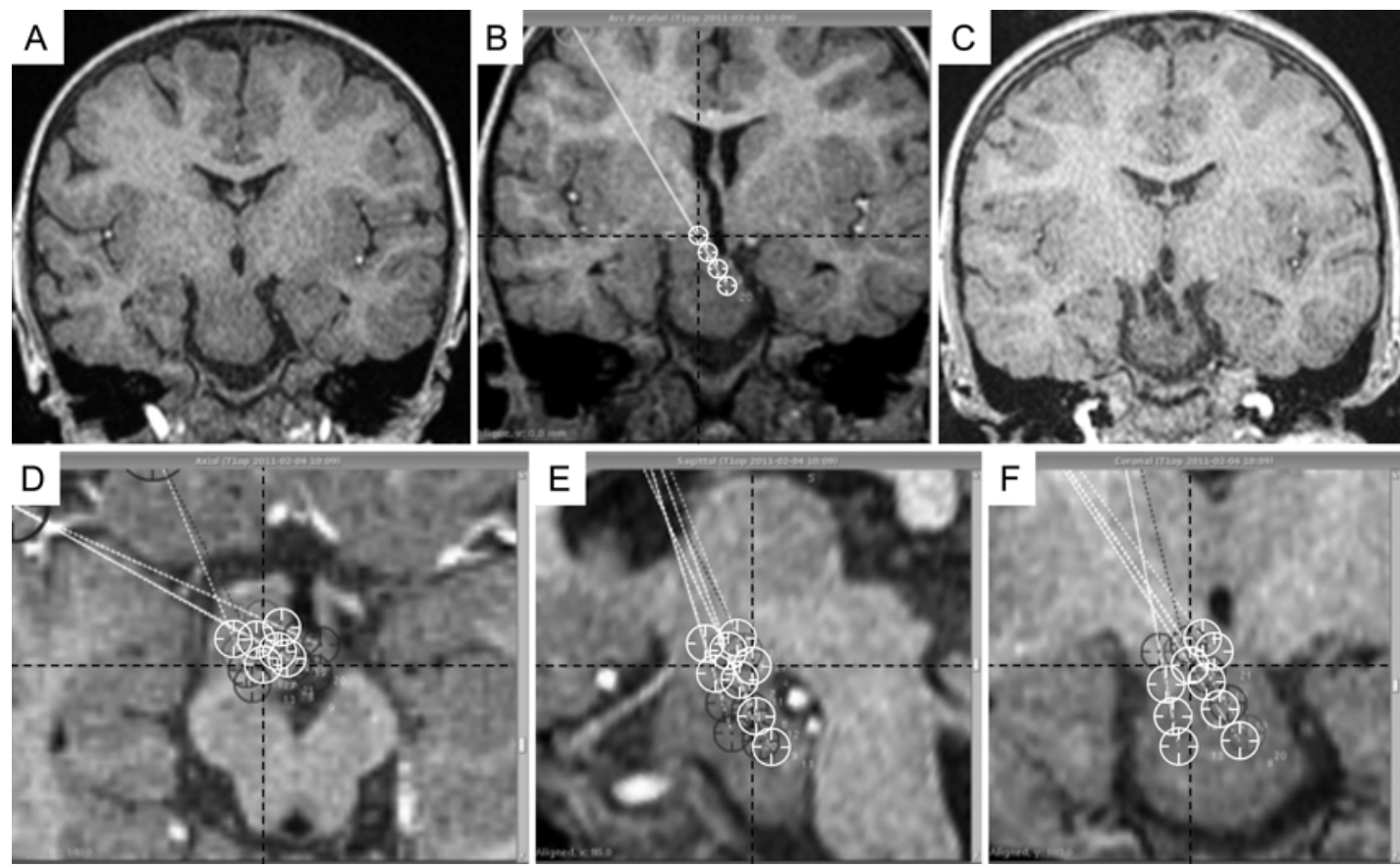

FIG. 1. Case 7. T1-weighted MR images illustrating the basic SRT procedure. The preoperative coronal MR image (A) shows a giant, mixed-type, bilaterally attached $\mathrm{HH}$ with left-sided dominant attachment to the hypothalamus. First, the trajectory of the coagulation probe is configured to make a coagulated lesion at the interface between the hamartoma and the hypothalamus. Then, the trajectory is elongated to cover the contralateral attachment as much as possible (coronal image, B). The trajectories are combined to cover the whole interface (D, axial image; E, sagittal; F, coronal). The postoperative coronal MR image obtained 1 year after SRT (C) shows that the coagulated lesion was made at the bilateral attachment of the hamartoma. Note that the coagulation is not performed for the whole hamartoma but intensively at the interface of the hamartoma and hypothalamus. This patient remained seizure-free until 3 years after SRT. The white and gray circles indicate the planned targets, each estimated as a 5-mm-diameter spherical coagulated lesion. The white and gray dotted lines represent the trajectories of the probe. Each MRI plane is fixed at the white target on the intersection of the vertical and transverse black dotted lines. The other white circles and dotted lines are located on or near the MRI plane. The gray circles and dotted lines indicate the targets and trajectories distant from the plane. 
ally planned for giant HHs to allow for creation of separate trajectories for treating the bilateral attachments, we developed a method involving a unilateral approach to the ipsilateral attachment and a trans-third ventricular approach to the contralateral attachment in a single-stage procedure and have been using this method since 2013 (Fig. 2). Repeat SRT procedures were performed for patients who had residual or recurrent GS, basing our decision on postoperative MRI performed at least 3 months after SRT. Because postoperative MRI performed immediately after SRT shows edema, swelling, and hemorrhage within the hamartoma, such a study is not appropriate for making decisions about residual hamartoma. The approach side was determined in the same way as for the first SRT, as described above. Repeat SRT was not performed for treatment of residual non-gelastic seizures.

\section{Follow-Up Study}

The patients were routinely followed up at 3 months, 1 year, 2 years, 3 years, and 5 years after SRT. Routine follow-up included EEG, MRI, neuropsychological tests, and endocrinological examination. Patients with residual GS also underwent video-EEG for confirmation of the seizures. Our main concern was whether seizures remained at the follow-up visits, and if so, which types of seizures they were. Seizure outcomes were classified by family members and the comprehensive epilepsy team as complete seizure freedom or lack of complete seizure freedom and evaluated in patients with at least 1 year of follow-up.
Some patients with apparent residual GS underwent repeat SRT within 1 year after the previous SRT. For patients who underwent multi-staged SRT procedures, the followup period was counted from the final SRT.

\section{Results \\ Clinical Characteristics}

The patients' median age at first SRT was 5 years (range 1-22 years). The mean maximum $\mathrm{HH}$ diameter was $38.5 \mathrm{~mm}$ (range $30-80 \mathrm{~mm}$ ). Overall, 15 patients showed mixed-type $\mathrm{HHs}$, and 1 patient had a parahypothalamictype $\mathrm{HH}$. Eleven HHs had bilateral attachments to the hypothalamus. All patients had GS. The median age at onset of GS was 0 years (range $0-4$ years), and the median age at onset of other seizure types was 1.75 years (range $0-11$ years). Non-gelastic seizure types included complex partial seizures, tonic seizures, atonic seizures, and generalized tonic-clonic seizures. Ten patients had only GS; 6 patients had non-gelastic seizures in addition to GS. Mental retardation, behavioral disorders, and precocious puberty were also present in $10(62.5 \%), 8(50.0 \%)$, and $11(68.8 \%)$ of the patients, respectively. Pallister-Hall syndrome was confirmed in 3 patients. Eight patients underwent previous interventions, including direct open resection (in 5 cases), endoscopic resection (in 1), SRT at another institute (in 1), and radiosurgery (in 6). Three of these patients had undergone multiple procedures before being treated with SRT at our institution. A summary of the patients' demographic and clinical characteristics is provided in Table 1.
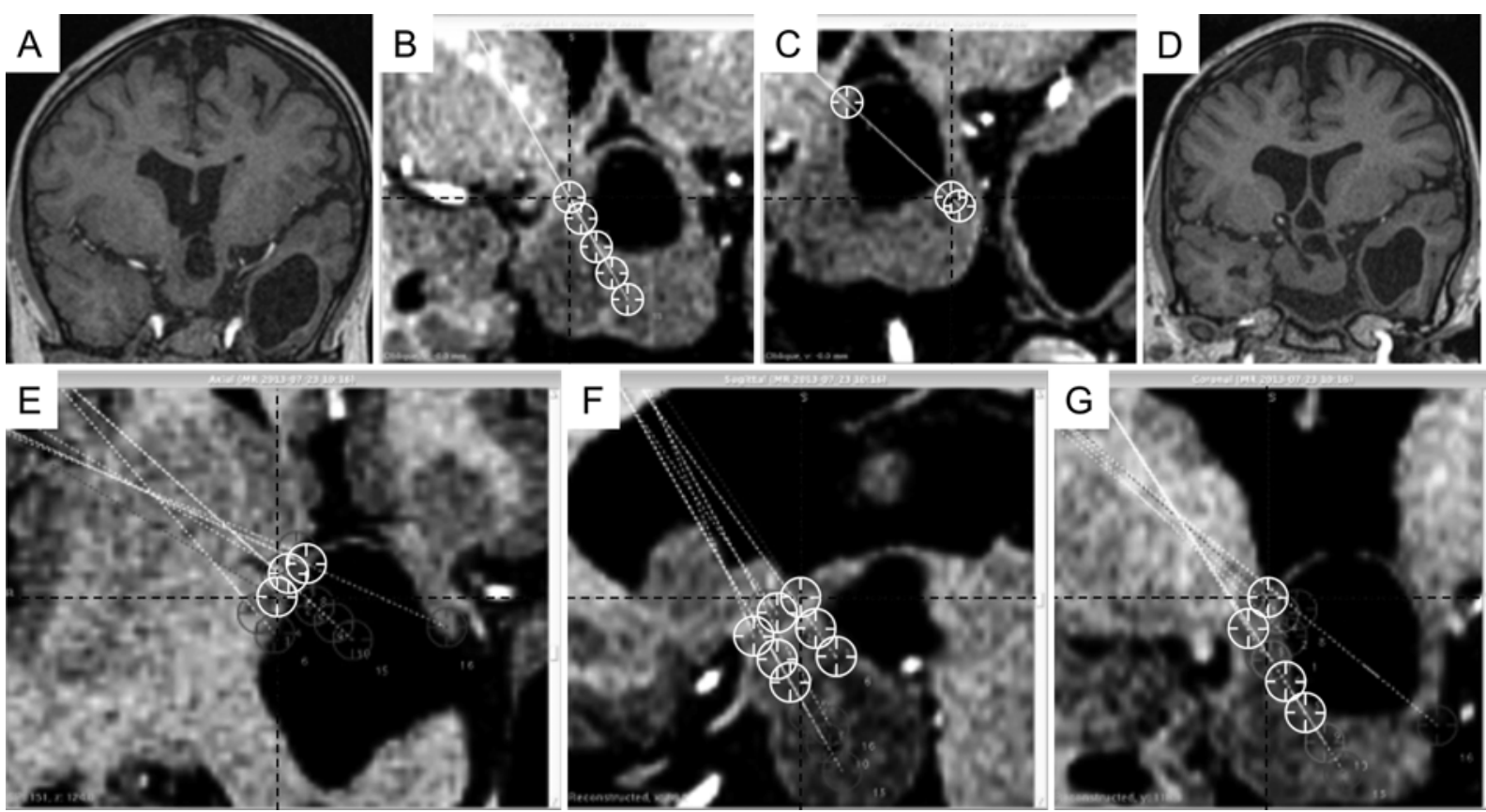

FIG. 2. Case 15. T1-weighted MR images illustrating SRT performed via the trans-third ventricular approach. The preoperative coronal MR image (A) shows a giant, mixed-type, bilaterally attached $\mathrm{HH}$ with a large cyst. The trajectory of the coagulation probe is planned to make coagulated lesions at the interface, as for basic SRT (B). Thereafter, the trajectory targeted to the contralateral attachment is configured through the third ventricle (C). The trajectories are combined to cover the whole bilateral interface $(\mathbf{E}$, axial; $\mathbf{F}$, sagittal; $\mathbf{G}$, coronal). The postoperative coronal MR image obtained 1 year after SRT (D) shows that the coagulated lesion was made not only at the operated side, but also at the contralateral attachment (G). This patient remained seizure-free at the 1-year follow-up evaluation. For details of what the circles and dotted lines indicate, see the Fig. 1 legend. 
TABLE 1. Demographic and clinical characteristics of 16 patients with giant HHs

\begin{tabular}{|c|c|c|c|c|c|c|c|c|c|c|c|c|c|c|}
\hline \multirow{2}{*}{$\begin{array}{c}\text { Case } \\
\text { No. }\end{array}$} & \multirow{2}{*}{$\begin{array}{l}\text { Pt } \\
\text { Sex }\end{array}$} & \multirow{2}{*}{$\begin{array}{l}\text { Age at } \\
\text { Op (yrs) }\end{array}$} & \multicolumn{3}{|c|}{ MRI Findings } & \multicolumn{2}{|r|}{ Sz Type } & \multicolumn{2}{|c|}{ Age at Onset (yrs) } & \multicolumn{3}{|c|}{ Comorbidities } & \multirow[b]{2}{*}{ Genetics } & \multirow{2}{*}{$\begin{array}{l}\text { Previous } \\
\text { Surgery }\end{array}$} \\
\hline & & & $\operatorname{Max} \operatorname{Diam}(\mathrm{mm})$ & Type* $^{*}$ & Attach & GS & Non-GS & GS & Non-GS & MR & $\mathrm{BD}$ & PP & & \\
\hline 1 & M & 4 & 30 & Mixed & Bilat & + & TS/GTCS & 1 & 3 & + & - & - & & None \\
\hline 2 & $\mathrm{~F}$ & 3 & 50 & Mixed & Rt & + & GTCS & 0 & 1 & - & - & + & & None \\
\hline 3 & M & 13 & 30 & Mixed & $\mathrm{Rt}$ & + & TS & 0 & 5 & + & + & + & & $\mathrm{D}, \mathrm{RS}, \mathrm{SRT} \dagger$ \\
\hline 4 & $\mathrm{~F}$ & 4 & 53 & Mixed & Bilat & + & TS/CPS & 0 & 3 & + & + & - & & $\mathrm{D}, \mathrm{E}, \mathrm{RS}$ \\
\hline 5 & $\mathrm{~F}$ & 22 & 30 & Mixed & $\mathrm{Lt}$ & + & CPS & 0 & 11 & - & - & + & & D \\
\hline 6 & $\mathrm{~F}$ & 13 & 30 & Mixed & Bilat & + & GTCS/AS & 1 & 0 & + & + & + & $\mathrm{PH}$ & D \\
\hline 7 & $\mathrm{~F}$ & 2 & 30 & Para & Rt & + & CPS/AS & 0 & 2 & + & - & + & & None \\
\hline 8 & $\mathrm{~F}$ & 4 & 80 & Mixed & Bilat & + & - & 4 & NA & + & + & - & $\mathrm{PH}$ & None \\
\hline 9 & M & 1 & 35 & Mixed & Bilat & + & TS & 0 & 0 & - & + & + & & None \\
\hline 10 & M & 13 & 31 & Mixed & Bilat & + & TS/GTCS/CPS & 0 & 0 & + & + & + & & $\mathrm{D}, \mathrm{RS}$ \\
\hline 11 & $\mathrm{~F}$ & 8 & 35 & Mixed & Bilat & + & TS & 0 & 3 & + & + & + & & RS \\
\hline 12 & M & 5 & 38 & Mixed & Bilat & + & TS/GTCS & 0 & 0 & - & + & - & & None \\
\hline 13 & $\mathrm{~F}$ & 7 & 35 & Mixed & $\mathrm{Lt}$ & + & CPS & 1.5 & 1.5 & - & + & + & & None \\
\hline 14 & M & 2 & 42 & Mixed & Bilat & + & - & 0 & NA & - & - & + & & RS \\
\hline 15 & $\mathrm{~F}$ & 10 & 35 & Mixed & Bilat & + & - & 2 & NA & - & + & + & $\mathrm{PH}$ & None \\
\hline 16 & $M$ & 5 & 32 & Mixed & Bilat & + & - & 0 & NA & - & - & - & & RS \\
\hline
\end{tabular}

$\mathrm{AS}=$ atonic seizure; attach = side of attachment to hypothalamus; $\mathrm{BD}=$ behavioral disorder; $\mathrm{CPS}=$ complex partial seizure; $\mathrm{D}=$ direct open surgery; diam = diameter; $\mathrm{E}=$ endoscopic surgery; GTCS = generalized tonic-clonic seizure; $\mathrm{MR}=$ mental retardation; NA = not applicable; para = parahypothalamic; $\mathrm{PH}=\mathrm{Pallister}-\mathrm{Hall}$ syndrome; $\mathrm{PP}$ = precocious puberty; RS = radiosurgery; $\mathrm{Sz}$ = seizure; $\mathrm{TS}$ = tonic seizure; + = present; - = absent.

* According to Kameyama's classification. ${ }^{19}$

$\dagger$ SRT at another institute.

\section{SRT Procedures}

A total of 22 SRT procedures were performed in the 16 patients included in this study (Table 2). Five patients underwent multistaged SRT. In the first SRT procedure, a mean of 5.9 tracks (range 3-10 tracks) and 17.9 coagulated lesions (range 6-36 lesions) were required. In the following 7 SRT procedures, a mean of 4.6 tracks (range 3-6 tracks) and 16.6 lesions (range 6-32 lesions) were necessary. After 17 of the 22 procedures, transient complications, including high fever $\left(\geq 38.5^{\circ} \mathrm{C}, \mathrm{n}=7\right)$, hyperphagia $(\mathrm{n}=3)$, hyponatremia $(\leq 130 \mathrm{mEq} / \mathrm{L}$, with some medical treatment, $\mathrm{n}=$ 6), consciousness disturbance $(\mathrm{n}=1)$, cyst enlargement ( $\mathrm{n}$ $=1)$, and epidural hematoma $(\mathrm{n}=1)$, were seen. All cases of high fever and hyponatremia improved within 2 weeks after SRT. Hyperphagia with weight gain remained at 3 months after SRT and then resolved. Horner's syndrome $(n=10)$ tended to remain in some patients even at 1 year's follow-up, although it decreased in all cases and did not impair the patients' quality of life. One patient (Case 8) who showed prolonged disturbance of consciousness after the second SRT procedure was found to have bilateral hypothalamic edema on MRI 1 week after SRT. Her level of consciousness gradually improved from 1 month after SRT and returned to her preoperative level (full recovery) at 3 months after SRT. One patient (Case 2) had a large cyst within the HH that enlarged after the first SRT. A cystoperitoneal shunt was inserted twice using stereotactic technique, and the cyst then decreased in size. One patient (Case 15) had an asymptomatic epidural hematoma that resolved spontaneously. There were no fatal outcomes.

Figures 3-5 show preoperative MR images, representa- tive SRT images, and the final postoperative MR images from Cases 1-6, 8-14, and 16. (Images from Cases 7 and 15 are shown in Figs. 1 and 2.) Postoperative MRI showed that the coagulations were made not in the whole hamartoma, but were focused at the border between the hamartoma and the hypothalamus.

\section{Seizure Outcomes}

The mean duration of follow-up was 24.1 months (range 12-60 months). Thirteen patients (81.3\%) achieved complete freedom from GS after the final SRT. Repeat SRT is planned for 2 of the 3 patients with residual GS in the near future; the remaining patient is under observation, but a decision has not yet been made regarding repeat SRT in this case. Of the 12 patients who had non-gelastic seizures, $7(58.3 \%)$ experienced freedom from these seizure types. Residual non-gelastic seizures included tonic seizures (in 4 patients) and generalized tonic-clonic seizures (in 2). One patient had both tonic and generalized tonic-clonic seizures. Overall seizure freedom was achieved in 10 cases $(62.5 \%)$. Seven patients were able to reduce their antiepileptic drug (AED) therapy, and 2 of them were able to discontinue AED treatment entirely.

\section{Discussion}

A total of 22 SRT procedures were performed in 16 patients with giant $\mathrm{HHs}$, and overall seizure freedom was achieved in $62.5 \%$ of the cases. In 13 patients (81.3\%), GS ceased completely after treatment. After 17 of the 22 SRT procedures, several complications, including Horner's syn- 


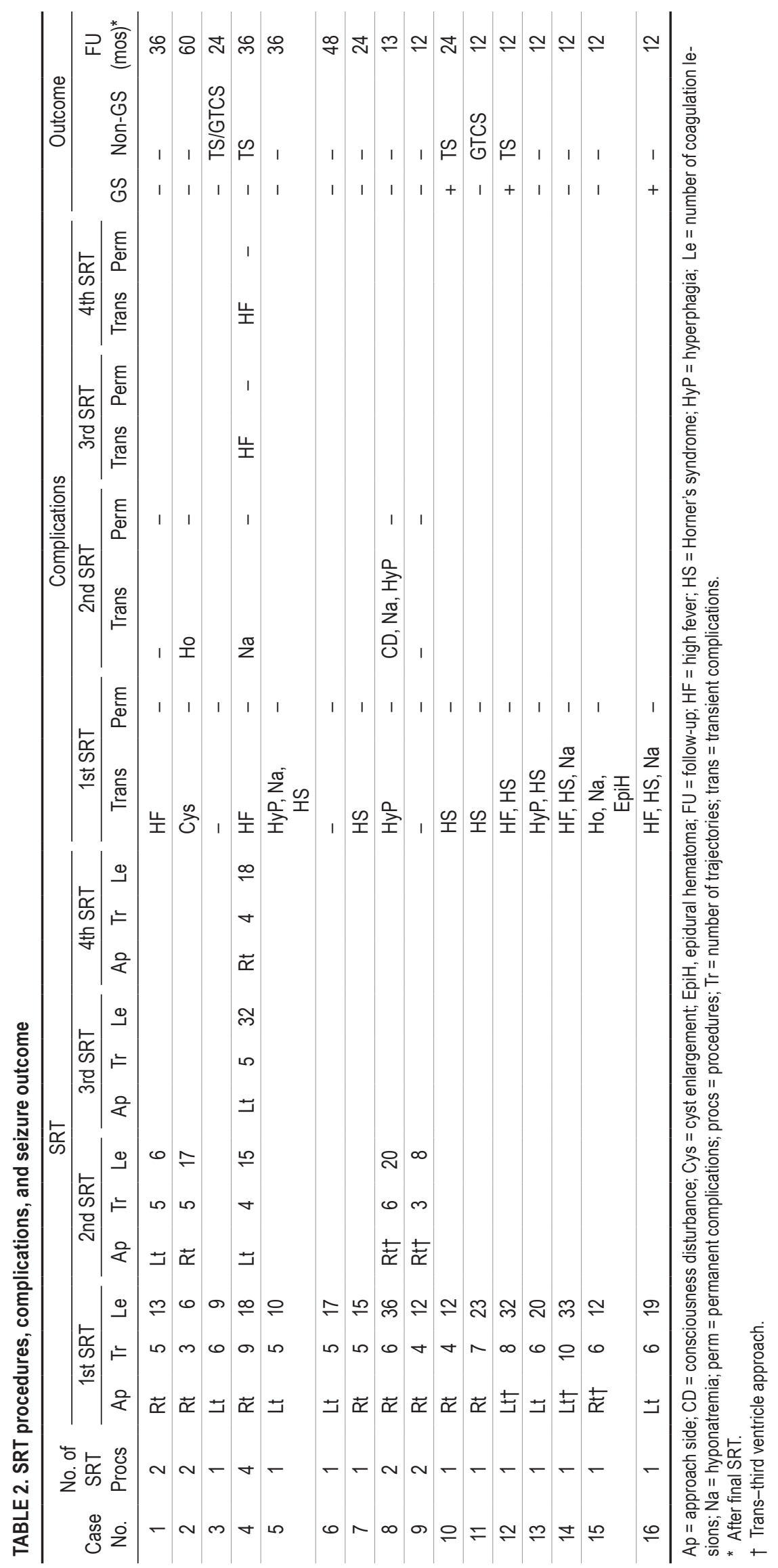



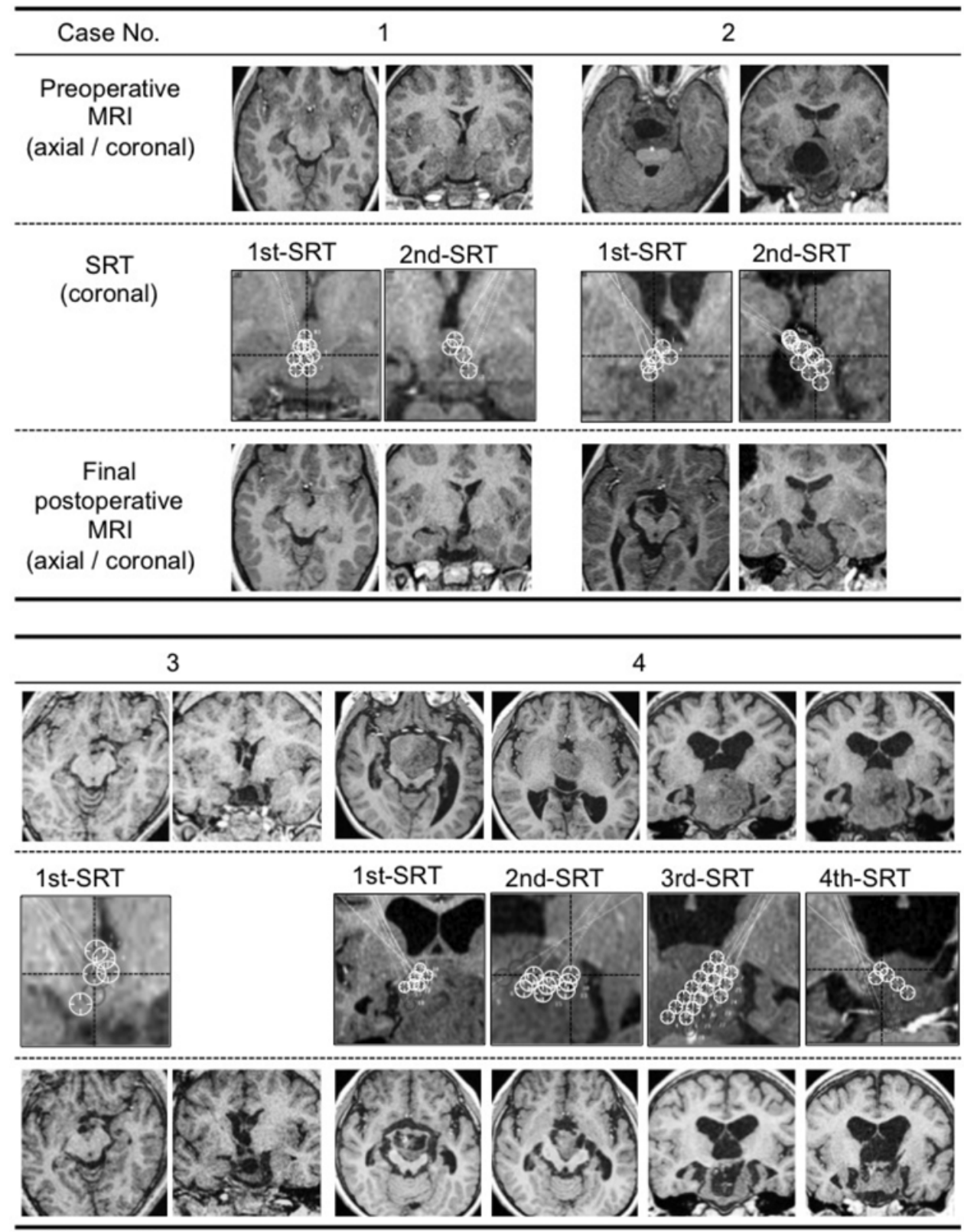

FIG. 3. Cases 1-4. Preoperative MR images (upper rows), representative images from the SRT procedures (middle rows), and final postoperative MR images (lower rows). In each set of preoperative or postoperative MR images, the axial image is on the left and the coronal image on the right. Two images are shown for both axial and coronal views in Case 4 in order to demonstrate the complex shape of this patient's extremely large $\mathrm{HH}$. Final postoperative MRI studies were performed at least 3 months after the final SRT. For details of what the circles and dotted lines indicate, see the Fig. 1 legend.

drome, high fever, hyperphagia, hyponatremia, consciousness disturbance, cyst enlargement, and epidural hematoma, were encountered. However, all of these complications were transient, and they did not result in long-term impairment of the patients' quality of life.

$\mathrm{HH}$ is an intrinsic epileptogenic lesion causing medically intractable epilepsy, characterized by unusual seizures, i.e., GS. ${ }^{10,12,16,18-20}$ HHs also cause various types of seizure other than GS as well as cognitive impairment and behavioral disorders. These problems are thought to be the effect of $\mathrm{HH}$ as secondary epileptogenesis or epileptic en- cephalopathy. ${ }^{4,21,36}$ Cognitive and behavioral problems are surgically remediable, so this pathophysiology is considered treatable epileptic encephalopathy. ${ }^{5,28,39}$ Direct open surgery, including a transcallosal, pterional, or orbitofrontal approach; ${ }^{14,26,31,37}$ endoscopic surgery; ${ }^{7,9,27}$ and radiosurgery $^{1,24,34}$ have all been performed for resection or disconnection of the HHs.

Surgical procedures for $\mathrm{HH}$ have been able to achieve seizure freedom or significant seizure reduction in approximately $50 \%-60 \%$ of cases, although they were frequently associated with some mortality or morbidity. Be- 

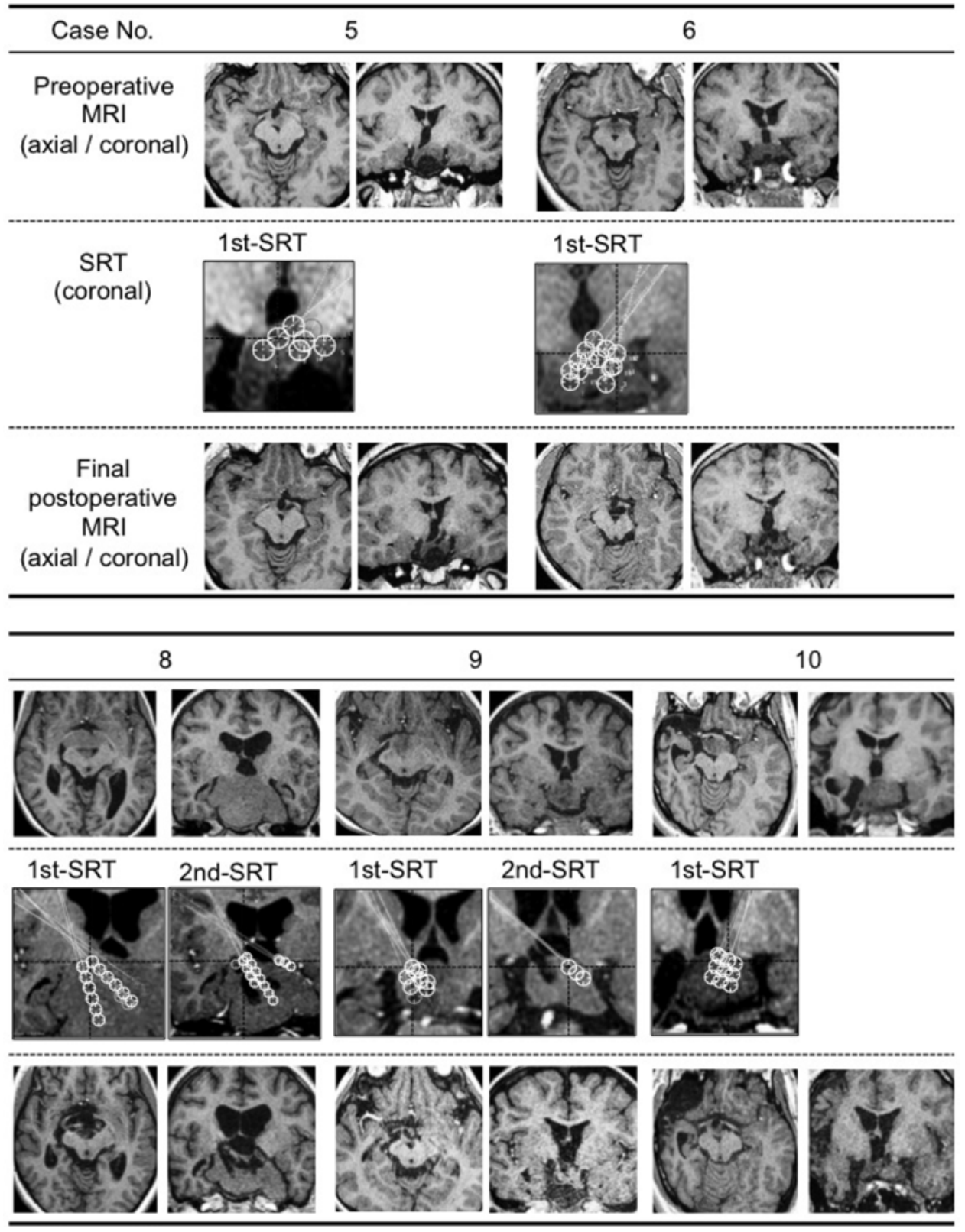

FIG. 4. Cases 5, 6, and 8-10. Preoperative MR images (upper rows), representative images from the SRT procedures (middle rows), and final postoperative MR images (lower rows). In each set of preoperative or postoperative MR images, the axial image is on the left and the coronal image on the right.

cause HHs are surrounded by numerous critical structures, such as major brain structures (hypothalamus, pituitary gland, mammillary body, fornix, cerebral peduncle), cranial nerves (optic tracts and oculomotor nerves), and major vessels, approaches to the HHs through the basal cistern or the ventricle carry a high risk of injury to these structures. Therefore, every surgical approach has inevitable risks of hypothalamic symptoms, hypopituitarism, memory problems, and stroke. ${ }^{26,28}$ Furthermore, the border between a hamartoma and normal hypothalamus is quite difficult to distinguish visually, making it difficult to achieve sufficient disconnection by a transventricular or endoscopic approach. Because sufficient disconnection of a hamartoma from the hypothalamus is essential for seizure freedom, incomplete disconnection may result in residual seizures. Gamma Knife surgery (GKS) has been used to treat HHs and has achieved passable seizure outcomes equivalent to surgical approaches. Radiosurgery has the great advantage of increased safety compared with resection or disconnection surgery, but it has limitations, because large or giant HHs are not appropriate for GKS. 1,24,35 Moreover, GKS has some disadvantages in immediate results, and some patients also experienced acute seizure exacerbation. ${ }^{34}$

\section{Safety and Efficacy of SRT}

The minimal invasiveness and efficacy of SRT for pa- 

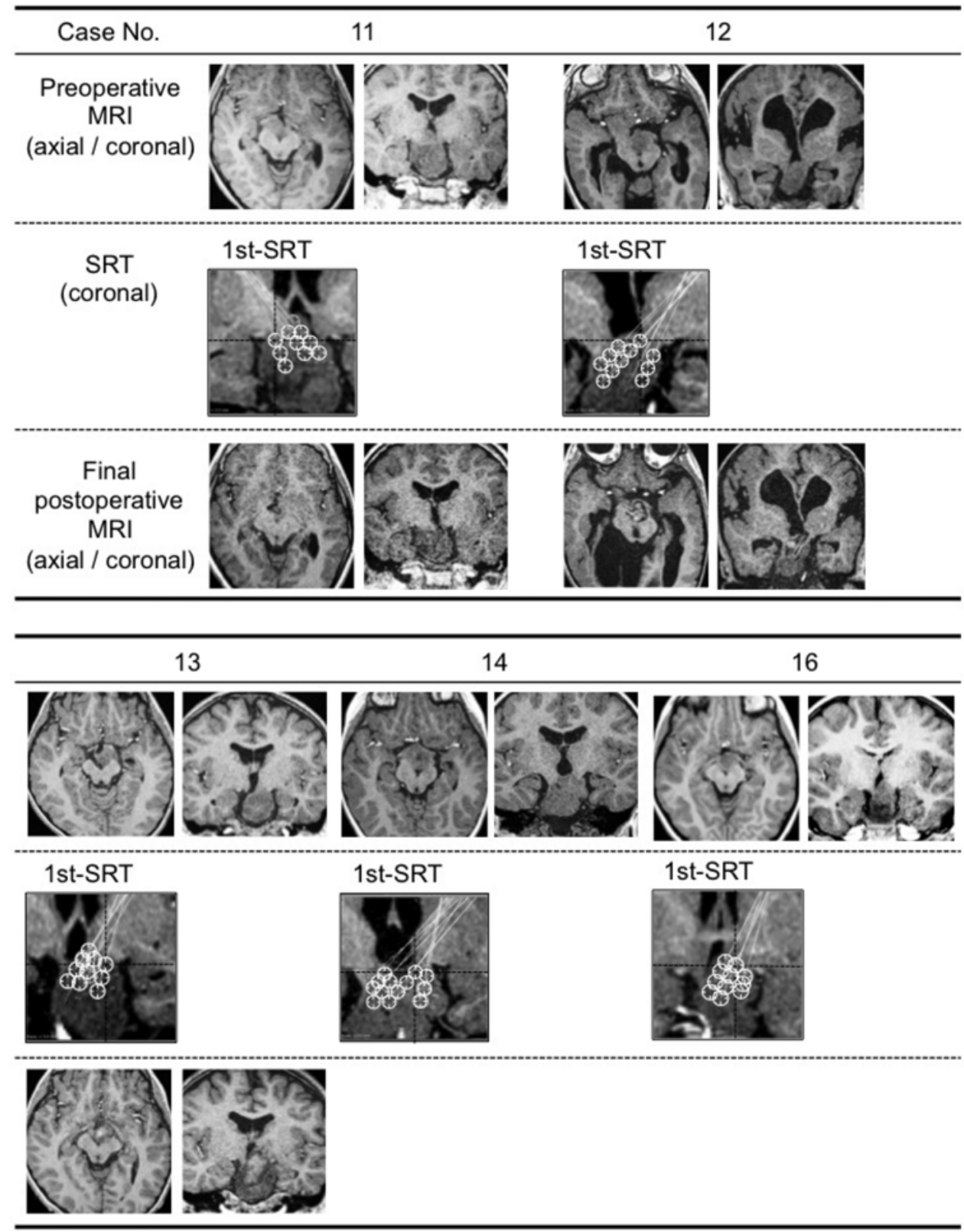

FIG. 5. Cases 11-14 and 16. Preoperative MR images (upper rows), representative images from the SRT procedures (middle rows), and final postoperative MR images (lower rows). In each set of preoperative or postoperative MR images, the axial image is on the left and the coronal image on the right.

tients with intractable epilepsy due to $\mathrm{HH}$ has been described in early reports. ${ }^{12,15,19}$ SRT is based on stereotactic technique, which guarantees accuracy and less invasiveness. Our SRT technique using 3D image planning software provides accurate targeting within 1-mm deviation confirmed by intraoperative fluoroscopy on each insertion of the trajectories. The diameter of the coagulated lesion is $5 \mathrm{~mm}$, which is equal to that of the sphere planned in SurgiPlan (Figs. 1 and 2). We check that the diameter of the coagulated lesion created by each coagulation probe is $5 \mathrm{~mm}$ by test-heating egg albumin before every SRT procedure. Therefore, the interface of the hamartoma can be disconnected according to the presurgical plan with great accuracy. The ultimate goal of the treatment of epilepsy due to $\mathrm{HH}$ is disconnection of the hamartoma from the hypothalamus, because $\mathrm{HH}$ is intrinsically epileptogenetic, and direct epileptic propagation to the hypothalamus and thalamus generates GS..$^{18}$ Although coagulations were not performed in the whole hamartoma, excellent seizure outcomes, better than with previously reported treatments, were achieved.

When patients are treated with SRT, the interface of the hamartoma can be disrupted without any damage to the critical structures outside the hamartoma. In SRT, the coagulation probe penetrates white matter and a small part of the basal ganglia, but such limited damage does not 
cause any neurological deficit, even when multiple tracks are used. The only risks are hemorrhage and edema of surrounding and penetrated tissues. There were no massive hematomas during the period of this study, only minimal bleeding across the coagulation probe tracks or within the coagulated lesion. Edema does occur around the coagulated lesion, and an effect on hypothalamic function can be expected. Most of our patients experienced signs of symptoms of hypothalamic dysfunction, such as high fever, hyperphagia, hyponatremia, Horner's syndrome, and memory disturbance. However, in all but 1 case, they were transient and improved quickly, usually within 2 weeks. One patient had a prolonged disturbance of consciousness, probably because of bilateral hypothalamic dysfunction due to bilateral coagulation in the second SRT, but even this patient had recovered fully by 3 months after SRT.

SRT has the advantage of having an immediate effect on seizure cessation if effective. This feature is superior to that of GKS, which has similar safety. For some patients it is sheer pleasure to have a seizure-free life immediately after treatment. The minimally invasive procedure of SRT can achieve this with minimal and transient adverse effects.

\section{Giant HH}

Comparatively large series have reported that the average size of HHs ranges from 14 to $19 \mathrm{~mm} .{ }^{3,11,29}$ Eleven cases of giant $\mathrm{HHs}$, defined as over $30 \mathrm{~mm}$, could be identified in the literature. . $, 8,13,16,23,25,27,32,33$ Some reports included giant HHs, although precise information was unavailable. ${ }^{11,29}$ We accumulated 16 cases in our own consecutive series. To the best of our knowledge, the present study is the first single specialized report of such a large number of surgically treated cases of giant HHs.

The past articles made negative comments about the surgical treatment of giant HHs. ${ }^{1,2}$ In most reports, the seizure outcomes were unfavorable, and surgical treatment of giant $\mathrm{HHs}$ was accompanied with a high incidence of complications. Because a giant $\mathrm{HH}$ has complex attachments and adheres to surrounding structures, surgical procedures other than SRT are characterized by difficulty in disconnecting or resecting the $\mathrm{HH}$ from the hypothalamus. Delalande and Fohlen classified giant HHs as Type IV in their classification system and mentioned that no specific surgical procedures can be recommended. ${ }^{7}$ GKS has also been described as unsuitable for giant HHs..$^{24,34}$ Some authors have mentioned that there was no single strategy for $\mathrm{HHs}$, or they recommended combination therapy regardless of the size or the shape of the HH. ${ }^{1,26,30,35}$ Their surgical procedures may have some limitations in the treatment of HHs.

SRT can coagulate the border of the hamartoma accurately, independent of size, shape, and location. In our series of giant HHs treated with SRT, a favorable outcome-freedom from GS-was achieved in 13 of 16 cases. Additionally, there were no permanent complications in any of the SRT procedures. SRT can be safely repeated for residual areas of connection between the $\mathrm{HH}$ and the hypothalamus; a total of 7 repeat SRT procedures were performed in 5 patients, and, furthermore, one of these patients underwent a total of 4 SRT procedures. Even in patients who underwent repeat SRT, there were no permanent complications, and the rate of transient complications did not increase. One patient who underwent a second SRT procedure for the treatment of residual bilateral attachments had a relatively prolonged but transient disturbance of consciousness. We hypothesized that severe edema occurred in hypothalamus bilaterally, causing the impaired consciousness. Giant HHs sometimes require aggressive treatment for complete disconnection, so that special care in the accuracy of targeting is needed. We guarantee accuracy by performing rigorous preplanning with $3 \mathrm{D}$ image planning software and by confirming the location of the inserted coagulation probe. Although early reports on SRT mentioned that it should be used for patients with small or medium-sized HHs, ${ }^{6,22,38}$ we consider that sophisticated SRT is the best single treatment for HHs, without any limitation of size, shape, or location.

\section{Conclusions}

We have reported on a series of 16 cases of giant HHs treated with SRT. Favorable seizure outcome was achieved without any permanent complications. We conclude that SRT is the best surgical treatment for HHs, even giant HHs.

\section{Acknowledgments}

We would like to thank Drs. Hiroatsu Murakami and Nobuo Satoh for their technical assistance. This study was supported in part by Health Labour Sciences Research Grant, the Ministry of Health, Labour and Welfare of Japan, and a research grant from the Japan Epilepsy Research Foundation.

\section{References}

1. Abla AA, Shetter AG, Chang SW, Wait SD, Brachman DG, $\mathrm{Ng}$ YT, et al: Gamma Knife surgery for hypothalamic hamartomas and epilepsy: patient selection and outcomes. J Neurosurg 113 Suppl:207-214, 2010

2. Alves C, Barbosa V, Machado M: Giant hypothalamic hamartoma: case report and literature review. Childs Nerv Syst 29:513-516, 2013

3. Arita K, Kurisu K, Kiura Y, Iida K, Otsubo H: Hypothalamic hamartoma. Neurol Med Chir (Tokyo) 45:221-231, 2005

4. Berkovic SF, Kuzniecky RI, Andermann F: Human epileptogenesis and hypothalamic hamartomas: new lessons from an experiment of nature. Epilepsia 38:1-3, 1997

5. Berkovic SF, Arzimanoglou A, Kuzniecky R, Harvey AS, Palmini A, Andermann F: Hypothalamic hamartoma and seizures: a treatable epileptic encephalopathy. Epilepsia 44:969-973, 2003

6. de Almeida AN, Fonoff ET, Ballester G, Teixeira MJ, Marino R Jr: Stereotactic disconnection of hypothalamic hamartoma to control seizure and behavior disturbance: case report and literature review. Neurosurg Rev 31:343-349, 2008

7. Delalande O, Fohlen M: Disconnecting surgical treatment of hypothalamic hamartoma in children and adults with refractory epilepsy and proposal of a new classification. Neurol Med Chir (Tokyo) 43:61-68, 2003

8. Dorfer C, Kasprian G, Mühlebner A, Czech T: Giant solidcystic hypothalamic hamartoma. Case report. Neurosurg Focus 30(2):E7, 2011

9. Drees C, Chapman K, Prenger E, Baxter L, Maganti R, Rekate H, et al: Seizure outcome and complications following hypothalamic hamartoma treatment in adults: endo- 
scopic, open, and Gamma Knife procedures. J Neurosurg 117:255-261, 2012

10. Fenoglio KA, Wu J, Kim Y, Simeone TA, Coons SW, Rekate $\mathrm{H}$, et al: Hypothalamic hamartoma: basic mechanisms of intrinsic epileptogenesis. Semin Pediatr Neurol 14:51-59, 2007

11. Freeman JL, Coleman LT, Wellard RM, Kean MJ, Rosenfeld JV, Jackson GD, et al: MR imaging and spectroscopic study of epileptogenic hypothalamic hamartomas: analysis of 72 cases. AJNR Am J Neuroradiol 25:450-462, 2004

12. Fukuda M, Kameyama S, Wachi M, Tanaka R: Stereotaxy for hypothalamic hamartoma with intractable gelastic seizures: technical case report. Neurosurgery 44:1347-1350, 1999

13. Guibaud L, Rode V, Saint-Pierre G, Pracros JP, Foray P, Tran-Minh VA: Giant hypothalamic hamartoma: an unusual neonatal tumor. Pediatr Radiol 25:17-18, 1995

14. Harvey AS, Freeman JL, Berkovic SF, Rosenfeld JV: Transcallosal resection of hypothalamic hamartomas in patients with intractable epilepsy. Epileptic Disord 5:257-265, 2003

15. Homma J, Kameyama S, Masuda H, Ueno T, Fujimoto A, Oishi M, et al: Stereotactic radiofrequency thermocoagulation for hypothalamic hamartoma with intractable gelastic seizures. Epilepsy Res 76:15-21, 2007

16. Hubbard AM, Egelhoff JC: MR imaging of large hypothalamic hamartomas in two infants. AJNR Am J Neuroradiol 10:1277, 1989

17. Kahane P, Ryvlin P, Hoffmann D, Minotti L, Benabid AL: From hypothalamic hamartoma to cortex: what can be learnt from depth recordings and stimulation? Epileptic Disord 5:205-217, 2003

18. Kameyama S, Masuda H, Murakami H: Ictogenesis and symptomatogenesis of gelastic seizures in hypothalamic hamartomas: an ictal SPECT study. Epilepsia 51:2270-2279, 2010

19. Kameyama S, Murakami H, Masuda H, Sugiyama I: Minimally invasive magnetic resonance imaging-guided stereotactic radiofrequency thermocoagulation for epileptogenic hypothalamic hamartomas. Neurosurgery 65:438-449, 2009

20. Kameyama S, Shirozu H, Masuda H, Ito Y, Sonoda M, Akazawa K: MRI-guided stereotactic radiofrequency thermocoagulation for 100 hypothalamic hamartomas. J Neurosurg [epub ahead of print November 20, 2015. DOI: 10.3171/2015.4.JNS1582]

21. Kerrigan JF, Ng YT, Chung S, Rekate HL: The hypothalamic hamartoma: a model of subcortical epileptogenesis and encephalopathy. Semin Pediatr Neurol 12:119-131, 2005

22. Kuzniecky RI, Guthrie BL: Stereotactic surgical approach to hypothalamic hamartomas. Epileptic Disord 5:275-280, 2003

23. López-Laso E, Mateos González ME, Camino León R, Jiménez González MD, Esparza Rodríguez J: Giant hypothalamic hamartoma and dacrystic seizures. Epileptic Disord 9:90-93, 2007

24. Mathieu D, Deacon C, Pinard CA, Kenny B, Duval J: Gamma Knife surgery for hypothalamic hamartomas causing refractory epilepsy: preliminary results from a prospective observational study. J Neurosurg 113 Suppl:215-221, 2010

25. Miranda P, Esparza J, Cabrera A, Hinojosa J: Giant hypothalamic hamartoma operated through subfrontal approach with orbitary rim osteotomy. Pediatr Neurosurg 42:254-257, 2006

26. Mittal S, Mittal M, Montes JL, Farmer JP, Andermann F: Hypothalamic hamartomas. Part 1. Clinical, neuroimaging, and neurophysiological characteristics. Neurosurg Focus 34(6):E6, 2013

27. Ng YT, Rekate HL: Successful third surgery for a case of sta- tus gelasticus: lessons learned after nearly 200 cases of hypothalamic hamartoma surgical resection. Epilepsia 52:e1-e3, 2011

28. Palmini A, Chandler C, Andermann F, Costa Da Costa J, Paglioli-Neto E, Polkey C, et al: Resection of the lesion in patients with hypothalamic hamartomas and catastrophic epilepsy. Neurology 58:1338-1347, 2002

29. Parvizi J, Le S, Foster BL, Bourgeois B, Riviello JJ, Prenger E, et al: Gelastic epilepsy and hypothalamic hamartomas: neuroanatomical analysis of brain lesions in 100 patients. Brain 134:2960-2968, 2011

30. Pati S, Abla AA, Rekate HL, Ng YT: Repeat surgery for hypothalamic hamartoma in refractory epilepsy. Neurosurg Focus 30(2):E3, 2011

31. Polkey CE: Resective surgery for hypothalamic hamartoma. Epileptic Disord 5:281-286, 2003

32. Prasad S, Shah J, Patkar D, Gala B, Patankar T: Giant hypothalamic hamartoma with cystic change: report of two cases and review of the literature. Neuroradiology 42:648-650, 2000

33. Razzaq AA, Chishti MK: Giant hypothalamic hamartoma and associated seizure types. J Pak Med Assoc 51:296-298, 2001

34. Régis J, Scavarda D, Tamura M, Nagayi M, Villeneuve N, Bartolomei F, et al: Epilepsy related to hypothalamic hamartomas: surgical management with special reference to gamma knife surgery. Childs Nerv Syst 22:881-895, 2006

35. Régis J, Scavarda D, Tamura M, Villeneuve N, Bartolomei F, Brue T, et al: Gamma knife surgery for epilepsy related to hypothalamic hamartomas. Semin Pediatr Neurol 14:73-79, 2007

36. Scholly J, Valenti MP, Staack AM, Strobl K, Bast T, Kehrli P, et al: Hypothalamic hamartoma: is the epileptogenic zone always hypothalamic? Arguments for independent (third stage) secondary epileptogenesis. Epilepsia 54 (Suppl 9):123-128, 2013

37. Wait SD, Abla AA, Killory BD, Nakaji P, Rekate HL: Surgical approaches to hypothalamic hamartomas. Neurosurg Focus 30(2):E2, 2011

38. Wang W, Wang W, Guo X, Zeng Y, Jiang X: Hypothalamic hamartoma causing gelastic seizures treated with stereotactic radiofrequency thermocoagulation. Epileptic Disord 11:333-338, 2009

39. Wethe JV, Prigatano GP, Gray J, Chapple K, Rekate HL, Kerrigan JF: Cognitive functioning before and after surgical resection for hypothalamic hamartoma and epilepsy. Neurology 81:1044-1050, 2013

\section{Disclosures}

The authors report no conflict of interest concerning the materials or methods used in this study or the findings specified in this paper.

\section{Author Contributions}

Conception and design: Shirozu, Kameyama. Acquisition of data: Shirozu, Masuda, Ito, Sonoda. Analysis and interpretation of data: Shirozu. Drafting the article: Shirozu. Critically revising the article: Shirozu. Reviewed submitted version of manuscript: Shirozu, Kameyama. Approved the final version of the manuscript on behalf of all authors: Shirozu. Study supervision: Kameyama.

\section{Correspondence}

Hiroshi Shirozu, 1-14-1, Masago, Nishi-ku, Niigata 950-2085, Japan. email: shirozu@masa.go.jp. 